\title{
Interleukin-1 receptor (IL-1R) mediates epilepsy-induced sleep disruption
}

\author{
Tzu-Rung Huang ${ }^{1 \dagger}$, Shuo-Bin Jou ${ }^{2 \dagger}$, Yu-Ju Chou ${ }^{1}$, Pei-Lu Yi ${ }^{3 *}$, Chun-Jen Chen ${ }^{4}$ and Fang-Chia Chang ${ }^{1,5,6^{*}}$
}

\begin{abstract}
Background: Sleep disruptions are common in epilepsy patients. Our previous study demonstrates that homeostatic factors and circadian rhythm may mediate epilepsy-induced sleep disturbances when epilepsy occurs at different zeitgeber hours. The proinflammatory cytokine, interleukin-1 (IL-1), is a somnogenic cytokine and may also be involved in epileptogenesis; however, few studies emphasize the effect of IL-1 in epilepsy-induced sleep disruption. We herein hypothesized that IL-1 receptor type 1 (IL-1R1) mediates the pathogenesis of epilepsy and epilepsyinduced sleep disturbances. We determined the role of IL-1R1 by using IL-1R1 knockout (IL-1R1 -/ - KO) mice.

Results: Our results elucidated the decrease of non-rapid eye movement (NREM) sleep during the light period in IL-1R -/ - mice and confirmed the somnogenic role of IL-1R1. Rapid electrical amygdala kindling was performed to induce epilepsy at the particular zeitgeber time (ZT) point, ZT13. Our results demonstrated that seizure thresholds induced by kindling stimuli, such as the after-discharge threshold and successful kindling rates, were not altered in IL-1R -/ - mice when compared to those obtained from the wildtype mice (IL-1R +/+ mice). This result suggests that IL-1R1 is not involved in kindling-induced epileptogenesis. During sleep, ZT13 kindling stimulation significantly enhanced NREM sleep during the subsequent $6 \mathrm{~h}$ (ZT13-18) in wildtype mice, and sleep returned to the baseline the following day. However, the kindling-induced sleep alteration was absent in the IL-1R - / - KO mice.
\end{abstract}

Conclusions: These results indicate that the IL-1 signal mediates epilepsy-induced sleep disturbance, but dose not participate in kindling-induced epileptogenesis.

Keywords: Amygdala, Epilepsy, IL-1 receptor, Kindling, Sleep

\section{Background}

Epilepsy results from the imbalance of excitability and inhibition of neuronal networks $[1,2]$. Patients with different types of epilepsy may experience either daytime sleepiness or nighttime sleep disturbance [3-6]. The prevalence of sleep disorders, such as excessive daytime sleepiness $[7,8]$, insomnia $[9,10]$ and obstructive sleep apnea $[8,10]$ is higher among patients with epilepsy.

Interleukin-1 $\beta$ (IL-1 $\beta$ ), one of the somnogenic factors, enhances non-rapid eye movement (NREM) sleep by

\footnotetext{
*Correspondence: pyi67@hotmail.com; fchang@ntu.edu.tw

${ }^{\dagger}$ Tzu-Rung Huang and Shuo-Bin Jou contributed equally to this work and should be considered cofirst authors

${ }^{1}$ Department of Veterinary Medicine, School of Veterinary Medicine, National Taiwan University, No. 1, Sec. 4., Roosevelt Road, Taipei 106, Taiwan

${ }^{3}$ Department of Sport Management, College of Tourism, Leisure and Sports, Aletheia University, New Taipei City, Taiwan

Full list of author information is available at the end of the article
}

acting at the basal forebrain [11] and the ventrolateral preoptic area (VLPO) [12]. Two types of IL-1 receptors (IL-1Rs) have been identified: the type 1 receptor (IL1R1) and the type 2 receptor (IL-1R2). IL-1R1 dominantly distributes throughout the brain and carries out the main function of NREM sleep enhancement [13]. IL-1R1 KO mice decrease sleep during the dark period of the light:dark cycle when compared with the wildtype mice [13]. IL-1 is also identified as one of the proinflammatory cytokines, which leads to the pathogenesis of epilepsy during inflammation. The concentrations of IL- $1 \beta$ increase and the number of IL- 1 receptors are up-regulated during seizures $[14,15]$. Existing evidence indicates that the increased concentrations of IL-1 $\beta$ may affect the seizure threshold, but the role of IL- $1 \beta$ in the epileptogenesis is still controversial, as both a proconvulsant and an anticonvulsant have been suggested. Growing evidence supports IL-1 as a proconvulsant substance. 
Seizure activities are inhibited after the injection of the IL-1 receptor antagonist (IL-1ra) and seizures are also suppressed in mice with over-expressed IL-1ra [14, 16]. On the other hand, the anticonvulsant effects of IL- 1 are also suggested in other studies. IL-1 augments the effect of gamma-aminobutyric acid (GABA)-A receptors and increases the pentylenetetrazol (PTZ)-induced seizure threshold in mice [17]. Intracerebroventricular (ICV) injections of IL-1 $\beta$ suppress the amygdaloid kindlinginduced seizures in rats [18]. Furthermore, IL-1 exhibits a temporal and dose-dependent influence on sleep regulation. Low doses of IL-1 increase NREM sleep during the night and slow wave activity during the day; in contrast, high doses of IL-1 suppress NREM sleep during the day and slow wave activity at night [19]. The opposite actions of high- and low-doses of IL-1 may explain the divergent effects. Because of the conflicts between those observations, the role of IL-1 in epileptogenesis needs to be further determined. We herein hypothesized that IL-1R1 mediates the pathogenesis of epilepsy and the epilepsyinduced sleep disturbances. In this study, we examined IL-1R1 in the kindling-induced epileptogenesis and sleep disruptions by employing IL-1R1 - / - mice.

Our previous results have demonstrated that epilepsy occurring at different zeitgeber time (ZT) points alters sleep differently [20, 21]. Kindled epilepsy at ZT0 decreases NREM sleep during the light period; in contrast, kindling stimulation at ZT13 increases NREM sleep during the dark period [20]. At ZT0, corticotropinreleasing hormone $(\mathrm{CRH})$ mediates kindling-induced NREM sleep reduction, and at ZT13, the increases in IL-1 are attributed to kindling-induced NREM sleep enhancement [20]. Furthermore, we further found that at ZT6, kindling epilepsy shifts the fluctuation of period circadian protein homolog 1 protein (PER1) in the suprachiasmatic nucleus (SCN) of the hypothalamus and alters sleep circadian rhythm [20]. These results suggest that epilepsy may alter either homeostatic factors or circadian rhythms to cause sleep disturbances. In this study, we further determined our hypothesis that at ZT13, IL-1R1 mediates kindling-induced sleep disruption by using IL-1R $1+/+$ and IL-1R 1 -/ - mice.

\section{Methods}

\section{Animals}

Male C57BL/6 (IL-1R1 +/+ and IL-1R1 -/-) mice (4to 6-weeks old) were used in present study. The original IL-1R1 -/- KO mice were obtained from Jackson Labo-

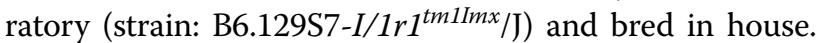
The wildtype C57BL/6 mice (IL-1R1 +/+) were purchased from BioLASCO Taiwan Co., Ltd. The polymerase chain reaction (PCR) analysis of brain tissue was performed to confirm the genotype of IL-1R1 $\mathrm{KO}$ mice used in experiments and to confirm any genetic drift during breeding (the detail genotyping methods as described later). All experiments and animal care were performed following the principles outlined in the Institutional Animal Care and Use Committee (IACUC) of National Taiwan University. Mice were anesthetized with zoletil $(20 \mathrm{mg} / \mathrm{kg}$, i.p.) and xylazine $(12 \mathrm{mg} / \mathrm{kg}$, i.p.), treated with antibiotics (penicillin $\mathrm{G}$ benzathine) to prevent infection, and surgically implanted with two electroencephalographic (EEG) electrodes (wire-wrapping-wire $30 \mathrm{AWG)}$ and a bipolar stimulating electrode. The placements of EEG electrodes were at the left frontal lobe and right parietal lobe. The bare ends of the insulated leads from the EEG electrodes were connected to Dupont female terminals and a $2.54 \mathrm{~mm} 2 \mathrm{P}$ Dupont connector. Bipolar insulated electrodes (model \# M148340, California fine wire company, Grover beach, CA) were placed in the left basolateral nucleus of the amygdala (BLA) as the target of kindling stimuli. The coordinates of the BLA were $1.9 \mathrm{~mm}$ caudal to bregma, $2.8 \mathrm{~mm}$ lateral to bregma, and $4.6 \mathrm{~mm}$ ventral to the dura [22]. The Dupont connector and bipolar electrodes were cemented to the skull with dental acrylic (Tempron, GC Co., Tokyo, Japan). Ibuprofen was added to their drinking water for 5 days after the surgery to reduce pain. Five days after the EEG implantation, the Dupont connector was connected to the amplifier system for habituation. All animals were housed separately in a recording cage and were housed in a 12:12 h light:dark (L:D) cycle in an isolated room where the temperature was maintained at $23 \pm 1{ }^{\circ} \mathrm{C}$. Food and water were provided ad libitum.

\section{PCR genotyping}

For the PCR genotyping analysis in each mouse, $0.5 \mathrm{~cm}$ sections of the tail tips were dissolved in $0.2 \mathrm{ml}$ of DirectPCR Lysis Reagent (Viagen Biotech) and $0.5 \mathrm{mg} / \mathrm{ml}$ of proteinase $\mathrm{K}$ (Roche) solutions under the following conditions: $55^{\circ} \mathrm{C}$ for $6-7 \mathrm{~h}, 85^{\circ} \mathrm{C}$ for $45 \mathrm{~min}, 25^{\circ} \mathrm{C}$ for $5 \mathrm{~min}$ ( 1 cycle), and then precipitated by centrifuging for $10 \mathrm{~s}$. One $\mu$ l of lysate was used for $50 \mu \mathrm{l}$ PCR reactions with MyTaq HS Mix (Bioline, Taunton, MA). We used the primers recommended by Jackson Laboratory for genotyping (Table 1). The expected PCR band for IL1R1 +/+ is $310 \mathrm{bps}$ and the band for IL-1R $1-/-$ is $150 \mathrm{bps}$. The heterozygous (IL-1R+/-) mice revealed both bands of 310 and 150 bps. PCR was performed by a C1000 thermocycler (BioRad, Hercules, CA). The parameters for reaction temperature cycles were $94{ }^{\circ} \mathrm{C}$ for $2 \mathrm{~min}$, and then 10 cycles of $94{ }^{\circ} \mathrm{C}$ for $20 \mathrm{~s}, 65^{\circ} \mathrm{C}$ for $15 \mathrm{~s}\left(-0.5{ }^{\circ} \mathrm{C}\right.$ decreases per cycle), and $68{ }^{\circ} \mathrm{C}$ for $10 \mathrm{~s}$, followed by 28 cycles of $94{ }^{\circ} \mathrm{C}$ for $15 \mathrm{~s}, 60{ }^{\circ} \mathrm{C}$ for $10 \mathrm{~s}$, and $72{ }^{\circ} \mathrm{C}$ for $10 \mathrm{~s}$. We analyzed $5 \mu \mathrm{l}$ of PCR reactions by using $1.5 \%$ agarose gel electrophoresis (agarose powders and $0.5 \times$ TBE buffer were purchased from Ameresco, Solon). All 
Table 1 The primer list

\begin{tabular}{lll}
\hline Primer & Sequence $\mathbf{5}^{\prime}$ to $\mathbf{3}^{\prime}$ & Primer type \\
\hline 10774 & CTCGTGCTTTACGGTATCGC & Mutant forward \\
20665 & GGTGCAACTTCATAGAGAGATGA & Wildtype forward \\
20666 & TTCTGTGCATGCTGGAAAC & Common \\
\hline
\end{tabular}

samples and DNA markers (100 bp DNA ladder, GeneDirex) were mixed with $6 \times$ loading buffers (GeneDirex novel juice) and slowly loaded into the slots of submerged gel in the electrophoresis chamber (Mupid-II; Cosmo Bio Co., Tokyo). The gels were run at $100 \mathrm{~V}$ for $20 \mathrm{~min}$. We examined the gel by UV illumination and photographed the gel as shown in Fig. 1. The primers are listed in Table 1. Mice used in this experiment were genotyped to confirm no genetic drift (Fig. 1).

\section{Kindling manipulation}

Nine days after surgery, mice were treated with rapid electrical amygdala kindling (REAK) [23, 24] to develop epilepsy. A 2-channel general-purpose stimulus generator (\#STG 4002, Multi Channel System MCS GmbH, Reutlingen, Germany) was used to deliver the kindling stimuli. The after-discharge threshold (ADT) was determined for each mouse by giving a series of stimulus intensities, which started from $20 \mu \mathrm{A}$ and increased by $20 \mu \mathrm{A}$ every $2 \mathrm{~min}$ until epileptiform after-discharge (AD) spikes appeared on EEGs within $10 \mathrm{~s}$ after the stimulation. AD spikes are defined as spikes of over $2 \mathrm{~Hz}$ and at least three times higher than the baseline EEG amplitude. Mice, not manifesting any $\mathrm{AD}$ spikes with a stimulus intensity of $250 \mu \mathrm{A}$ were excluded from the experiment. The intensity of kindling stimuli depended on individual ADT intensity of each mouse. A total of 40 stimuli were given through the bipolar electrode into the BLA. The stimulus was a train of monophasic pulses (1-ms duration each) of $100 \mathrm{~Hz}$ for $3 \mathrm{~s}$, and the stimulation was given every $5 \mathrm{~min}$ over a total of $200 \mathrm{~min}$. The severity of seizures was scored according to the 7 grade modifications of Racine's classification: stage 1, facial clonus; stage 2, head nodding; stage 3 , unilateral forelimb

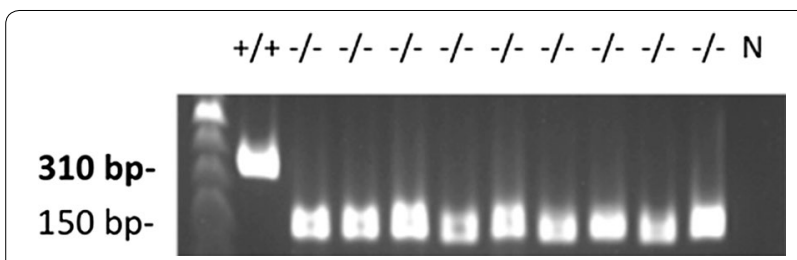

Fig. $1 \mathrm{LL}-1 \mathrm{R} 1$ expression of the cerebral hemispheres from IL-1R $+/+$ and -/- mice. $-/-$ represents IL-1R1 -/- mice; +/+ refers to wildtype mice. $N$ indicates the negative control clonus; stage 4, rearing with bilateral forelimb clonus; stage 5, rearing and falling (loss of postural control); stage 6 , running or bouncing seizures; stage 7 , tonic hind limb extension $[25,26]$. Mice that exhibited epileptiform EEGs induced by a single stimulus with the intensity of $300 \mu \mathrm{A}$ at ZT13 after the REAK protocol were considered as a successful induction of epilepsy by kindling.

\section{Experimental protocols}

Two groups of mice were used in this study. Group 1 $(\mathrm{n}=13)$ was used to determine the normal sleep and sleep alteration induced by kindling in wildtype (IL-1R1 $+/+)$ mice at ZT13 and group $2(\mathrm{n}=18)$ was used to determine the kindling-induced sleep disturbance in the IL-1R1 - / - mice at ZT13. All recordings started at the beginning of the dark period (ZT13) and continued for $24 \mathrm{~h}$ (ZT13-ZT24 and ZT1-ZT12). A 24-h baseline EEG was acquired as the control before the REAK protocol, and no electrical impulses were given at any time before and throughout the baseline recording. Then, 40 stimuli of REAK were given through the bipolar electrode into the left basolateral amygdala (BLA). Mice in all groups received a ZT13-kindling stimulus on the next day (the day of seizure induction) after the REAK procedure. Until epileptiform spikes induced by the ZT13-kindling manifested on EEGs, the mice were continuously recorded for 2 days (1st- and 2nd-day after seizure induction) to evaluate their sleep alteration.

\section{Statistical analysis for sleep recordings}

All values of sleep recordings are presented as mean \pm standard error of the mean (SEM). Repeated measures analysis of variance (ANOVA) was performed to analyze the differences in the vigilance states and sleep-architecture parameters across the dark period, light period and specific time blocks. If statistically significant differences were detected, post hoc (Duncan's) multiple range tests were used. An $\alpha$ level of $p$ value $<0.05$ was taken as indicating a statistically significant difference between groups.

\section{Statistical analysis for seizure threshold}

All ADT intensities are presented as mean \pm SEM. Twoway ANOVA was performed to evaluate the differences of ADT intensities between groups, and between successful-kindled and failure-kindled mice. The successful rate of kindling is presented as the percentage. Fisher's exact test was performed to compare the successful kindling rates between groups. Mann-Whitney $U$ test was used to examine the differences of Racine's stage seizures in successful-kindled mice. The $p$ value $<0.05$ was taken as indicating a statistically significant difference between groups. 


\section{Results}

The role of IL-1R1 in kindling-induced epileptogenesis

The ADT intensities, successful rates of kindling and Racine's stages of seizure were used to determine the changes in seizure thresholds. Table 1 delineated the results of ADT intensities and the successful rates of kindling. Some mice failed to develop epilepsy, even though they exhibited an AD spike. The ADT intensities between successful-kindled mice and failure-kindled mice were not significantly altered in two groups $(p=0.52)$. The average ADT intensity for success-kindled IL-R1 +/+ mice was $52.7 \pm 10.2 \mu \mathrm{A}(\mathrm{n}=11)$, and was $50 \pm 10.0 \mu \mathrm{A}$ $(\mathrm{n}=2)$ for failure-kindled IL-1R1 +/+ mice. In IL-1R1 $-/-$ mice, the average ADT intensity of success-kindled mice was $69.2 \pm 14.8 \mu \mathrm{A}(\mathrm{n}=13)$ and that of failure-kindled mice was $100 \pm 29.7 \mu \mathrm{A}(\mathrm{n}=5)$. The ADT intensities between IL-1R1 +/+ and IL-1R1 -/ - mice were not significantly different (Table 2 ).

The successful rates of developing epilepsy by kindling stimuli in the IL-1R1 +/+ and IL-1R1 -/- were 84.6 (11 out of 13 ) and $72.2 \%$ (13 out of 18$)$, respectively. The successful rates of developing epilepsy in two groups of mice were unremarkable $(p=0.73)$.

The seizures were scored by Racine's stage scores. No statistically significant difference among the median scores of Racine's stage between IL-1R1 +/+ and IL-1R1 - / - mice was discovered. The median scores of Racine's stage in two groups were the same, which were rated as grade 2 ( $\mathrm{n}=11$ for wildtype, $\mathrm{n}=13$ for IL-1R1 -/-; $p=0.6829)$.

\section{Sleep difference between IL-1R $1+/+$ and -/- mice}

During the undisturbed condition, IL-1R1 -/- mice exhibited significantly lower NREM sleep during the light period when compared to IL-1R1 +/+ mice. REM sleep was also significantly lower in the IL-1R1 -/- mice during the light period when compared to IL-1R $1+/+$ mice. There was no difference in both NREM and REM sleep during the dark period when comparing between IL-1R1 $+/+$ and IL-1R1 -/ - mice. The time spent in NREM sleep during the 12 -h light period was $50.5 \pm 1.7 \%$ in IL-1R $1+/+$ mice and $34.8 \pm 1.5 \%$ in IL-1R $1-/-$ mice $(p<0.05$ vs. IL-1R $1+/+$; Fig. $2 \mathrm{a})$. The time spent in REM sleep during the 12 -h light period was $8.9 \pm 0.6 \%$ in IL-1R $1+/+$ mice and $4.2 \pm 0.4 \%$ in IL-1R $1-/-$ mice ( $p<0.05$ vs. IL-1R1 +/+; Fig. 2b).

ZT13 kindling-induced sleep alterations in IL-1R1 +/+ mice ZT13 kindling stimulation significantly enhanced NREM sleep during ZT13-18 on the 1st-day after seizure induction in IL-1R1 +/+ mice (Fig. 3a). The amount of NREM sleep during ZT13-18 was increased from $11.7 \pm 2.3$ (obtained before receiving the ZT13 kindling stimulation,

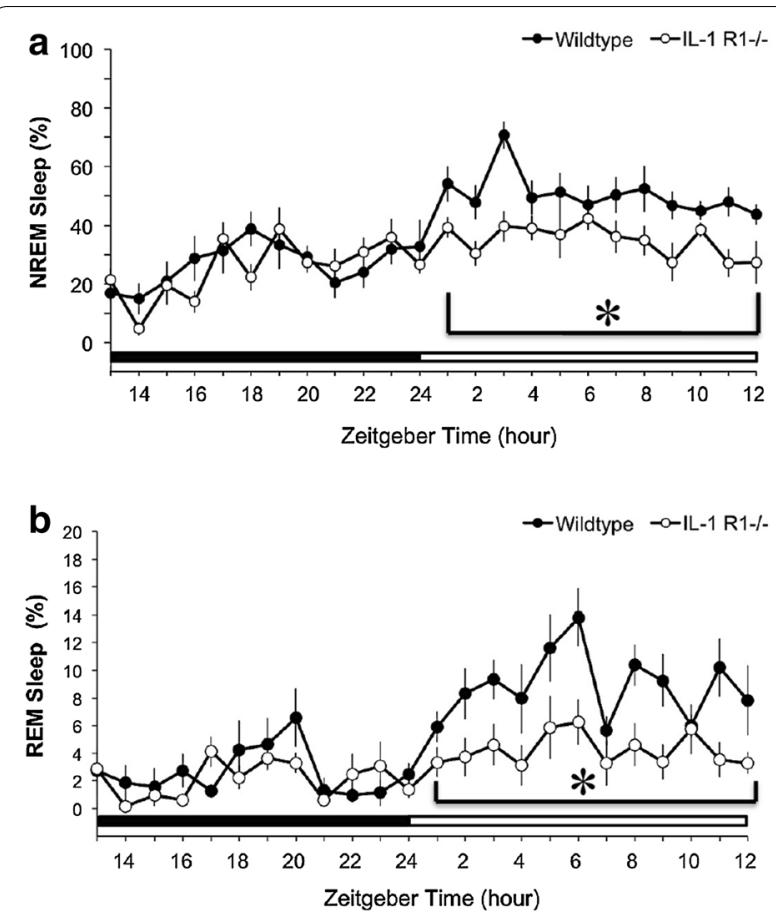

Fig. 2 Sleep difference between IL-1R1 +/+ and IL-1R1 -/- mice. $\mathbf{a}$ Represents the data of NREM sleep and $\mathbf{b}$ indicates the values of REM sleep. Closed circles represent the data obtained from the IL-1R1 $+/+$ mice, and open circles represent the data obtained from the IL-1R1 -/- mice. Asterisk refers to a statistically significant difference between two groups. The black bar indicates the 12-h dark period and the white bar indicates the 12 -h light period

Table 2 Results of seizure threshold in two groups of mice

\begin{tabular}{|c|c|c|c|c|c|c|c|}
\hline \multirow[t]{2}{*}{ Group } & \multicolumn{2}{|c|}{ Success kindled } & \multirow[t]{2}{*}{ Success kindling rate, \% } & \multicolumn{2}{|c|}{ Failure kindled } & \multirow[t]{2}{*}{ Failure kindling rate, $\%$} & \multirow[t]{2}{*}{ Total (n) } \\
\hline & (n) & $\mathrm{ADT}, \mu \mathrm{A}$ & & (n) & $\mathrm{ADT}, \mu \mathrm{A}$ & & \\
\hline Wildtype & 11 & $52.7 \pm 10.2$ & 84.6 & 2 & $50.0 \pm 10.0$ & 15.4 & 13 \\
\hline IL-1R1 -/- & 13 & $69.2 \pm 14.8$ & 72.7 & 5 & $100.0 \pm 29.7$ & 27.3 & 18 \\
\hline
\end{tabular}

Values of ADT are mean \pm SEM. ADT differences were detected by two-way ANOVA

Values of rates are presented as percentage. Fisher's exact test was performed to compare the difference between two groups of mice 

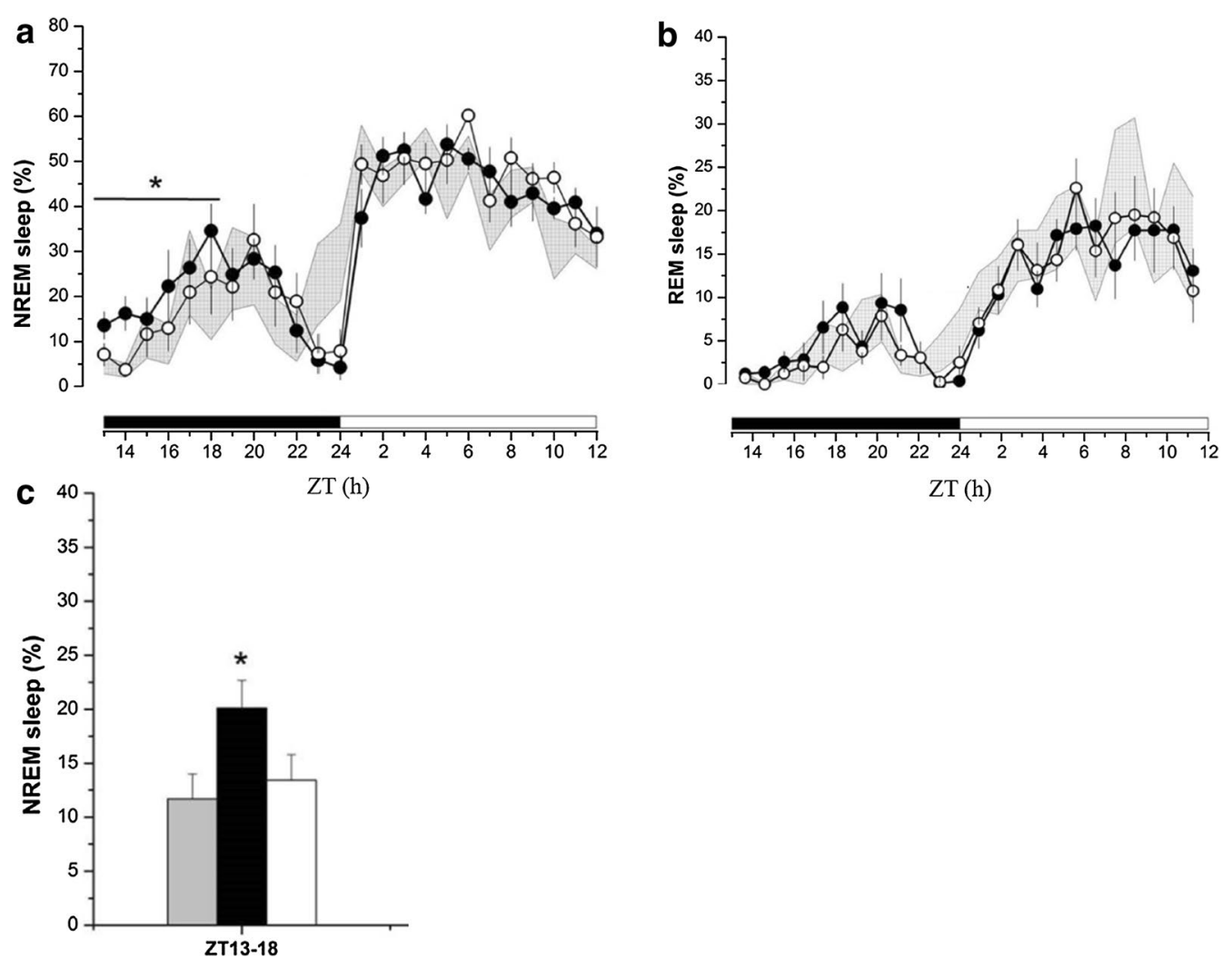

Fig. 3 The effects of ZT13 kindling stimuli on sleep alterations in wildtype mice. a ZT13 kindling stimuli enhanced NREM sleep during ZT13-18 in the 1st-day after seizure induction, but there was no change on the following day. b ZT13 kindling stimulation did not alter REM sleep. Shadow areas represents the data obtained from baseline control, closed circles represent the data acquired from the 1st-day after seizure induction, and the open circles represents the 2nd-day after seizure induction. c The summary of NREM sleep alteration after ZT13 kindling stimuli. The grey bar represents the data obtained from control, the black bar represents the data acquired from the 1st-day after seizure induction, and the white bar represents the data obtained from the 2 nd-day after seizure induction. Asterisk refers to a statistically significant difference between control and the 1st-day after seizure induction. Sleep-wake activity was recorded from the beginning of the dark period (ZT13) and lasted for $24 \mathrm{~h}$

the baseline control) to $20.1 \pm 2.6 \%(\mathrm{n}=8)$ on the $1 \mathrm{st}$ day after seizure induction ( $p<0.05$ vs. baseline control), and returned to $13.5 \pm 2.4 \%$ on the 2 nd-day after seizure induction ( $p>0.05$ vs. baseline control; Fig. 3a, c). The difference of NREM sleep acquired before and after kindling stimulation is $8.6 \pm 2.5 \%$. ZT13 kindling stimulation did not alter REM sleep during both dark and light periods on the 1st- and 2nd-day after seizure induction (Fig. 3b).

ZT13 kindling-induced sleep alterations in IL-1R1 -/- mice In IL-1R1 -/- mice, ZT13 kindling stimulation did not have significant impact on NREM sleep during ZT13-18 (Fig. 4a). The time spent in NREM sleep during ZT1318 was $12.7 \pm 2.9 \%$ before receiving the ZT13 kindling stimulation (the baseline control), $15.5 \pm 3.9 \%$ ( $p>0.05$ vs. baseline control) from the 1st-day after seizure induction, and $11.7 \pm 3.4 \%$ ( $p>0.05$ vs. baseline control) from the 2nd-day after seizure induction (Fig. 4a, c). The difference between NREM sleep acquired before and after kindling stimulation is $2.5 \pm 2.6 \%(p<0.05$ vs. the difference obtained from IL-1R1 +/+ mice). Effects of ZT13 kindling stimulation on REM sleep and wakefulness did not reach statistical significance during any of the time blocks (Fig. 4b). The percentages of REM sleep during ZT13-18 obtained from the baseline, the 1st-day, and the 2nd-day after seizure induction were $1.2 \pm 0.4,2.6 \pm 0.6$ ( $p>0.05$ vs. baseline control), and $3.0 \pm 0.9 \%$ ( $p>0.05$ vs. baseline control), respectively.

\section{Discussion}

Many epileptic patients suffer from sleep disturbances, which enormously reduce their quality of life $[8,9,27]$. Although the comorbidity of epilepsy and sleep disorders is generally evidenced, the underlying mechanisms have yet to be clarified. This study investigated the roles 

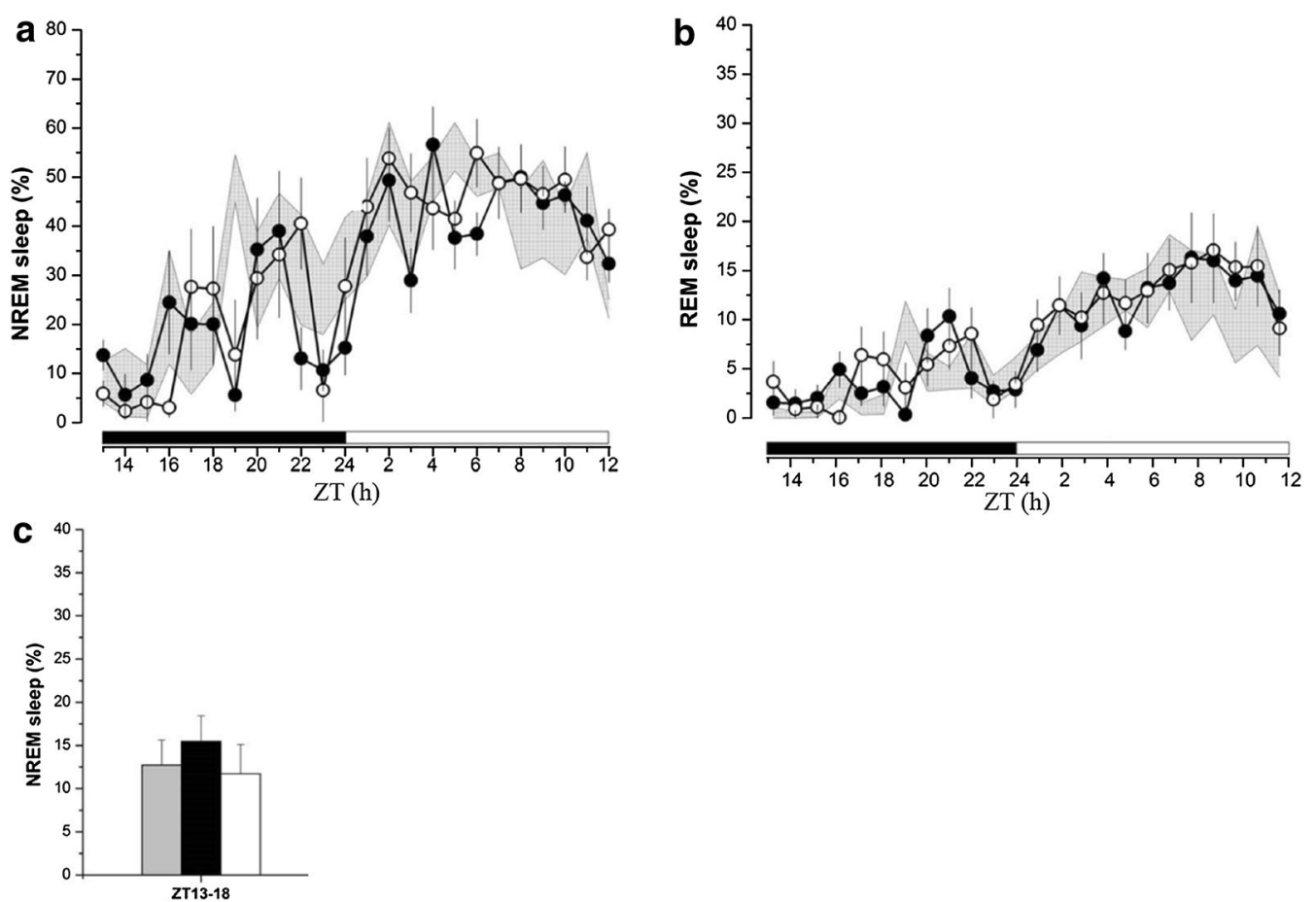

Fig. 4 The effects of ZT13 kindling stimuli on sleep alterations in IL-1R1 -/- mice. a ZT13 kindling stimuli did not change NREM sleep during ZT1318 in the 1st- and 2nd-day after successful kindling. b ZT13 kindling stimulation did not alter REM sleep either. Shadow areas represents the data obtained from baseline control, closed circles represent the data acquired from the 1st-day after seizure induction, and the open circles represents the 2nd-day after seizure induction. c The summary of NREM sleep alteration after ZT13 kindling stimuli. The grey bar represents the data obtained from control, the black bar represents the data acquired from the 1st-day after seizure induction, and the white bar represents the data obtained from the 2 nd-day after seizure induction. Sleep-wake activity was recorded from the beginning of the dark period (ZT13) and lasted for $24 \mathrm{~h}$

of IL-1R1 in the thresholds of kindling-induced epileptogenesis and in the kindling-induced sleep disturbances. An IL-1R1 KO mouse was the ideal model to explore the role of IL-1; the difference in parameters can be examined when there is a lack of IL-1 signaling.

The theory assumed to interpret the discrepant role of IL-1 in epileptogenesis derives from the variability of IL-1 concentrations and the complexity of IL-1 downstream cytokines. Therefore, the transgenic IL-1R1 KO mouse is an excellent model to examine the significance of IL-1 when its signal in the brain is completely eliminated. Much evidence also supports the proconvulsant role of IL-1 in epilepsy. In rat models, systemic administration of IL-1ra reduces seizures induced by hippocampal kindling or pilocarpine [14]. In transgenic mice, bicuculline methiodine-induced seizure decreases in IL-1ra overexpressed mice, and the seizure threshold in heatinginduced febrile seizure is increased in IL-1R1 $-/-$ mice $[16,28]$. IL-1 may enhance seizures by facilitating LTP in the hippocampus; however, it is also suggested that as the dosage is increased, IL-1 performs the opposite role and suppresses LTP $[29,30]$. A recently published paper further describes that the pathogenesis and maintenance of temporal lobe epilepsies are attributed to the activation of P2X7 receptors by the release of ATP during neurodegeneration, which activates the microglia to release IL-1 $\beta$ [31]. In contrast, the anticonvulsant role of IL- $1 \beta$ has also been suggested in BLA-kindling rats, as evidenced by the decrease in seizures after ICV injection of IL- $1 \beta$ [18]. Our current results indicate no change in the seizure thresholds in kindling epileptogenesis in mice with a lack of IL-1R1. These results suggest that IL-1R1 is not a critical factor in influencing kindling-induced epileptogenesis. However, our other study demonstrated that IL-1R1 contributes to the epileptogenesis when epilepsy is induced by pentylenetetrazol (PTZ) (personal unpublished result).

IL-1 $\beta$ is one of the potent somnogenic factors. It's been reported that NREM sleep during the dark period is reduced in IL-1R1 KO mice when comparied to the wildtype mice [13]. In our results, we found that both NREM and REM sleep were reduced during the light period, rather than during the dark period. IL- $1 \beta$ exhibits circadian fluctuation with higher concentrations during the light period and with lower concentrations during the dark period [32]. A lack of IL-1 signaling should affect 
sleep during the light period, and our results provided the evidence to support the somnogenesis of IL-1 signaling. The increase of NREM sleep after ZT13 kindling stimulus in the wildtype mice, but not in the IL-1R1 KO mice revealing the importance of IL-1 receptors in epilepsy-induced sleep alterations. During the first $6 \mathrm{~h}$ following ZT13 kindling stimulus (ZT13-18), NREM sleep obtained from the wildtype mice increased. These alterations returned to the baseline value on the 2nd day. In transgenic knockout mice, kindling stimulation did not alter NREM sleep during first $6 \mathrm{~h}$.

During neuronal damage, the expression of IL- $1 \beta$ and its receptors are increased, and IL- $1 \beta$ signaling pathways are activated when encountering pathological damage $[15,33]$. The activation of IL- $1 \beta$ function may facilitate neuronal excitability by modulating long-term potentiation (LTP) and inhibitory GABA receptors in hippocampal areas $[17,30]$. Besides affecting synaptic plasticity, the increase of IL- $1 \beta$ influences both NREM sleep and REM sleep. Administration of IL- $1 \beta$ into the CNS, or peripheral circulated system, significantly enhances NREM sleep [34]. But when the dose of IL- $1 \beta$ reaches a pathogenic concentration, the opposite result occurs in which both NREM sleep and REM sleep are suppressed $[35,36]$. The common phenomenon that NREM sleep increases and REM sleep is suppressed during inflammation in individual is in accordance with the results of IL- $1 \beta$ administration [37]. This conjecture explains the close link between sleep and the immune system, and it helps interpret our results that NREM sleep increased after ZT13 kindling in wildtype mice, but not IL-1R1 KO mice.

The increases of sleep after seizures have also been reported in pilocarpine-induced epileptic rats. Administration of pilocarpine enhances and fragments slow wave sleep in the following night and morning, and returns to normal after 24 h [38]. Quigg et al. [39] demonstrated that deep NREM sleep increases following one kindling stimulus, and lasts even longer after 5 times of accumulated kindling stimuli. In our previous study, the seizure occurrence time is considered as a critical factor in determining the ways to alter sleep; kindling stimulation at ZT0 decreases NREM sleep, whereas ZT13 kindling stimulation enhances NREM sleep [18, 20]. IL-1 mRNA expression increases in the hippocampus and cortex after ZT13 kindling stimulus and the increase of NREM sleep is blocked by administration of IL-1ra $[20,21]$. Nevertheless, our current study demonstrated that a lack of IL- 1 signals in the IL-1R1 $-/-$ mice failed to express the ZT13-induced sleep enhancement. Furthermore, different IL-1 signals may lead to different outcomes between epilepsy and sleep. For example, IL-1 activates both p38 mitogen-activated protein kinase
(MAPK) and nuclear factor $\kappa \mathrm{B}(\mathrm{NF}-\mathrm{kB})$ pathways in astrocytes, but only regulates p38 MAPK pathways in the hippocampal neurons [40]. Particularly, a lower dose of IL-1 phosphorylates Src kinase in the hippocampal neurons [40]. Furthermore, different isoforms of the IL-1 receptor accessory proteins also mediate different signal pathways [40]; however, the mechanisms need to be further determined. Astrocytes and neurons contribute to both epileptogenesis and sleep regulation. Different IL-1 signaling outcomes could explain why IL-1R1 plays a role in sleep alteration, but not in epileptogenesis in kindled mice.

\section{Conclusions}

In summary, our results demonstrated the essential role of IL-1R1 in kindling-induced sleep disturbance by using transgenic IL-1R1 KO mice. Epilepsy-induced sleep disturbances were absent in the IL-1R1 KO mice, indicating the importance of IL-1 signals. The knockout of IL-1R1 did not change the seizure thresholds, suggesting that IL-1R1 signaling is not in involved in the kindlinginduced epileptogenesis.

\section{Abbreviations}

AD: after-discharge; ADT: after-discharge threshold; BLA: basolateral nucleus of amydgala; CRH: corticotropin-releasing hormone; EEG: electroencephalography; GABA: gamma-aminobutyric acid; ICV: intracerebroventricular; IL-1: interleukin-1; IL-1R1: IL-1 receptor type 1; IL-1 ra: IL-1 receptor antagonist; KO: knockout; LTP: long-term potentiation; NREM: non-rapid eye movement; PCR: polymerase chain reaction; PER1: period circadian protein homolog 1 protein; PTZ: pentylenetetrazol; REAK: rapid electrical amygdala kindling; REM: rapid eye movement; SCN: suprachiasmatic nucleus; VLPO: ventrolateral preoptic area; ZT: zeitgeber time.

\section{Authors' contributions}

$T R, S B, P L$ and FC contribute to the experimental designs, TR and $Y J$ collect experimental data and analyze the data, CJ provides the IL-1R1 - / - mice, and $T R, S B, P L$ and FC are responsible for the manuscript writing and revising. All authors read and approved the final manuscript.

\section{Author details}

${ }^{1}$ Department of Veterinary Medicine, School of Veterinary Medicine, National Taiwan University, No. 1, Sec. 4., Roosevelt Road, Taipei 106, Taiwan. ${ }^{2}$ Department of Neurology, Mackay Memorial Hospital and Mackay Medical College, Taipei, Taiwan. ${ }^{3}$ Department of Sport Management, College of Tourism, Leisure and Sports, Aletheia University, New Taipei City, Taiwan. ${ }^{4}$ Department of Biochemical Science and Technology, College of Life Science, National Taiwan University, Taipei, Taiwan. ${ }^{5}$ Graduate Institute of Brain and Mind Sciences, College of Medicine, National Taiwan University, Taipei, Taiwan. ${ }^{6}$ Graduate Institute of Acupuncture Science, College of Chinese Medicine, China Medical University, Taichung, Taiwan.

\section{Acknowledgements}

Authors thank Mr. Brian Chang (University of Rochester) and Miss Emily

Chang (Morrison Academy) for their help with English revision. This work was supported by Ministry of Science and Technology Grants NSC99-2320-B-002026-MY3 and MOST105-2320-B-002-059-MY3.

\section{Competing interests}

The authors declare that they have no competing interests. 


\section{Availability of data and materials}

The full dataset supporting in the conclusion of this article can be obtained upon request to the corresponding author at fchang@ntu.edu.tw.

\section{Ethical approval}

All experiments were approved by Institutional Animal Care and Use Committee (IACUC) of National Taiwan University and were performed in accordance with the Guideline for the Care and Use of Laboratory Animals.

\section{Funding}

This work was supported by Ministry of Science and Technology Grants NSC99-2320-B-002-026-MY3 and MOST105-2320-B-002-059-MY3.

Received: 15 August 2016 Accepted: 14 November 2016

Published online: 22 November 2016

\section{References}

1. Badawy RA, Harvey AS, Macdonell RA. Cortical hyperexcitability and epileptogenesis: understanding the mechanisms of epilepsy-part 1. J Clin Neurosci. 2009:16:355-65.

2. Fisher RS, van Emde Boas W, Blume W, Elger C, Genton P, Lee P, et al. Epileptic seizures and epilepsy: definitions proposed by the International League Against Epilepsy (ILAE) and the International Bureau for Epilepsy (IBE). Epilepsia. 2005:46:470-2.

3. Malow BA, Bowes RJ, Lin X. Predictors of sleepiness in epilepsy patients. Sleep. 1997;20:1105-10.

4. Crespel A, Baldy-Moulinier M, Coubes P. The relationship between sleep and epilepsy in frontal and temporal lobe epilepsies: practical and physiologic considerations. Epilepsia. 1998:39:150-7.

5. Montplaisir J, Laverdière M, Saint-Hilaire JM, Rouleau I. Nocturnal sleep recordings in partial epilepsy: a study with depth electrodes. J Clin Neurophysiol. 1987:4:383-8.

6. Stores G, Wiggs L, Campling G. Sleep disorders and their relationship to psychological disturbances in children with epilepsy. Child Care Health Dev. 1998;24:5-19.

7. Giorelli AS, Neves GS, Venturi M, Pontes IM, Valois A, Gomes Mda M. Excessive daytime sleepiness in patients with epilepsy: a subjective evaluation. Epilepsy Behav. 2011;21:449-52.

8. Piperidou C, Karlovasitou A, Triantafyllou N, Terzoudi A, Constantinidis T, Vadikolias K, et al. Influence of sleep disturbance on quality of life of patients with epilepsy. Seizure. 2008;17:588-94.

9. Vendrame M, Yang B, Jackson S, Auerbach SH. Insomnia and epilepsy: a questionnaire-based study. J Clin Sleep Med. 2013;9:141-6.

10. Jain SV, Simakajornboon N, Glauser TA. Provider practices impact adequate diagnosis of sleep disorders in children with epilepsy. J Child Neurol. 2013:28:589-95.

11. Alam MN, McGinty D, Bashir T, Kumar S, Imeri L, Opp MR, et al. Interleukin-1 beta modulates state-dependent discharge activity of preoptic area and basal forebrain neurons: role in sleep regulation. Eur J Neurosci. 2004;20:207-16.

12. Baker FC, Shah S, Stewart D, Angara C, Gong H, Szymusiak R, et al. Interleukin $1 \beta$ enhances non-rapid eye movement sleep and increases c-Fos protein expression in the median preoptic nucleus of the thalamus. Am J Physiol Regul Integr Comp Physiol. 2005;288:R998-1005.

13. Fang J, Wang Y, Krueger JM. Effects of interleukin-1 beta on sleep are mediated by the type I receptor. Am J Physiol Regul Integr Comp Physiol. 1998:274:R655-60.

14. Marchi N, Fan Q, Ghosh C, Fazio V, Bertolini F, Betto G, et al. Antagonism of peripheral inflammation reduces the severity of status epilepticus. Neurobiol Dis. 2009;33:171-81.

15. Ravizza T, Vezzani A. Status epilepticus induces time-dependent neurona and astrocytic expression of interleukin-1 receptor type I in the rat limbic system. Neuroscience. 2006;137:301-8.

16. Vezzani A, Moneta D, Conti M, Richichi C, Ravizza T, De Luigi A, et al. Powerful anticonvulsant action of IL-1 receptor antagonist on intracerebral injection and astrocytic overexpression in mice. Proc Natl Acad Sci USA. 2000;97:11534-9.
17. Miller LG, Galpern WR, Dunlap K, Dinarello CA, Turner TJ. Interleukin-1 augments gamma-aminobutyric acid A receptor function in brain. Mol Pharmacol. 1991;39:105-8.

18. Sayyah M, Beheshti S, Shokrgoza MA, Eslami-far A, Deljoo Z, Khabiri AR, et al. Antiepileptogenic and anticonvulsant activity of interleukin-1 beta in amygdala-kindled rats. Exp Neurol. 2005;191:145-53.

19. Opp MR, Obal F Jr, Krueger JM. Interleukin 1 alters rat sleep: temporal and dose-related effects. Am J Physiol. 1991;260:R52-8.

20. Yi PL, Chen YJ, Lin CT, Chang FC. Occurrence of epilepsy at different zeitgeber times alters sleep homeostasis differently in rats. Sleep. 2012;35:1651-65.

21. Yi PL, Tsai CH, Lin JG, Lee CC, Chang FC. Kindling stimuli delivered at different times in the sleep-wake cycle. Sleep. 2004;27:203-12.

22. Franklin KBJ, Paxinos G. The mouse brain in stereotaxic coordinates. 2nd ed. New York: Academic press; 2001

23. Sashindranath M, McLean KJ, Trounce IA, Cotton RGH, Cook MJ. Early hippocampal oxidative stress is a direct consequence of seizures in the rapid electrical amygdala kindling model. Epilepsy Res. 2010;90:285-94.

24. Smith PD, McLean KJ, Murphy MA, Turnley AM, Cook MJ. Functional dentate gyrus neurogenesis in a rapid kindling seizure model. Eur J Neurosci. 2006;24:3195-203.

25. He XP, Minichiello L, Klein R, McNamara JO. Immunohistochemical evidence of seizure-induced activation of trkB receptors in the mossy fiber pathway of adult mouse hippocampus. J Neurosci. 2002;22:7502-8.

26. Racine RJ. Modification of seizure activity by electrical stimulation. II. Motor seizure. Electroencephalogr Clin Neurophysiol. 1972;32:281-94.

27. Xu X, Brandenburg NA, McDermott AM, Bazil CW. Sleep disturbances reported by refractory partial-onset epilepsy patients receiving polytherapy. Epilepsia. 2006:47:1176-83.

28. Dube C, Vezzani A, Behrens M, Bartfai T, Baram TZ. Interleukin-1 beta contributes to the generation of experimental febrile seizures. Ann Neurol. 2005;57:152-5

29. del Rey A, Balschun D, Wetzel W, Randorf A, Besedovsky HO. A cytokine network involving brain-borne IL-1 beta, IL-1 ra, IL-18, IL-6, and TNF alpha operates during long-term potentiation and learning. Brain Behav Immun. 2013:33:15-23.

30. Ross FM, Allan SM, Rothwell NJ, Verkhratsky A. A dual role for interleukin-1 in LTP in mouse hippocampal slices. J Neuroimmunol. 2003:144:61-7.

31. Jimenez-Pacheco A, Diaz-Hernandez M, Arribas-Blázquez M, San-Rodriguez A, Olivos-Oré LA, Artalejo AR, et al. Transient P2X7 receptor antagonism produces lasting reductions in spontaneous seizures and gliosis in experimental temporal lobe epilepsy. J Neurosci. 2016;36:5920-32.

32. Kapsimalis F, Richardson G, Opp MR, Kryger M. Cytokines and normal sleep. Curr Opin Pulm Med. 2005:11:481-4.

33. Allan SM, Tyrrell PJ, Rothwell NJ. Interleukin-1 and neuronal injury. Nat Rev Immunol. 2005:5:629-40.

34. Clinton JM, Davis CJ, Zielinski MR, Jewett KA, Krueger JM. Biochemical regulation of sleep and sleep biomarkers. J Clin Sleep Med. 2011;7:S38-42.

35. Brambilla D, Barajon I, Bianchi S, Opp MR, Imeri L. Interleukin-1 inhibits putative cholinergic neurons in vitro and REM sleep when microinjected into the rat laterodorsal tegmental nucleus. Sleep. 2010;33:919-29.

36. Gemma C, Imeri L, de Simoni MG, Mancia M. Interleukin-1 induces changes in sleep, brain temperature, and serotonergic metabolism. Am J Physiol Regul Integr Comp Physiol. 1997:272:R601-6.

37. Krueger JM, Majde JA. Humoral links between sleep and the immune system: research issues. Ann N Y Acad Sci. 2003:992:9-20.

38. Matos G, Tsai R, Baldo MV, de Castro I, Sameshima K, Valle AC. The sleepwake cycle in adult rats following pilocarpine-induced temporal lobe epilepsy. Epilepsy Behav. 2010;17:324-31.

39. Quigg M, Straume M, Smith T, Menaker M, Bertram EH. Seizures induce phase shifts of rat circadian rhythms. Brain Res. 2001:913:165-9.

40. Huang Y, Smith DE, Ibáñez-Sandoval O, Sims JE, Friedman WJ. Neuronspecific effects of interleukin-1 $\beta$ are mediated by a novel isoform of the IL-1 receptor accessory protein. J Neurosci. 2011;31:18048-59. 